\title{
Aldosterone Blocks Rat Stem Leydig Cell Development In Vitro
}

\author{
Jingwei Zhang ${ }^{1 \dagger}$, Bisheng Huang ${ }^{1 \dagger}$, Guanghui Hu${ }^{1 \dagger}$, Xiangcheng Zhan ${ }^{2}$, Tiancheng Xie ${ }^{1}$, \\ Saiyang $\mathrm{Li}^{2}$, Xiaolu Zhang ${ }^{1}$, Huitao $\mathrm{Li}^{3}$, Ren-Shan $\mathrm{Ge}^{3 *}$ and Yunfei $\mathrm{Xu}^{1 *}$ \\ ${ }^{1}$ Department of Urology, Shanghai Tenth People's Hospital, Tongji University, Shanghai, China, ${ }^{2}$ Department of Urology, \\ Shanghai Tenth People's Hospital, Nanjing Medical University, Nanjing, China, ${ }^{3}$ Center of Scientific Research, \\ The Second Affiliated Hospital and Yuying Children's Hospital of Wenzhou Medical University, Wenzhou, China
}

OPEN ACCESS

Edited by:

Katja Teerds,

Wageningen University,

Netherlands

Reviewed by:

T. Rajendra Kumar,

University of Colorado Anschutz Medical Campus, United States

John Clulow,

University of Newcastle, Australia Eddy Rijntjes,

Charité Universitätsmedizin Berlin, Germany

*Correspondence:

Ren-Shan Ge

rge@yahoo.com;

Yunfei Xu

xuyunfeibb@sina.com

tThese authors have contributed equally to this work

Specialty section: This article was submitted to Reproduction,

a section of the journal

Frontiers in Endocrinology

Received: 09 October 2017 Accepted: 05 January 2018

Published: 24 January 2018

Citation:

Zhang J, Huang B, Hu G, Zhan X, Xie T, Li S, Zhang X, LiH, Ge R-S and XU Y (2018) Aldosterone Blocks Rat Stem Leydig Cell Development In Vitro.

Front. Endocrinol. 9:4. doi: 10.3389/fendo.2018.00004
Aldosterone (ALDO) is a primary endogenous mineralocorticoid, appearing as the main hormone controlling sodium and water homeostasis. Its emerging role in the development of many organs has gained interest over the past few years. In the testis, Leydig cells contain mineralocorticoid receptors and ALDO stimulates androgen synthesis via the mineralocorticoid receptors in rat adult Leydig cells. Although ALDO pharmacologically promoted the Leydig cell function, its role in Leydig cell development was unclear. In the present study, we investigated effects of ALDO on rat stem Leydig cell (SLC) proliferation and differentiation. Using an in vitro culture system of the seminiferous tubules from Leydig cell-depleted testis and EdU (a modified thymidine analog) incorporation into the SLC for flurorescent labeling to judge its DNA synthesis and measurement of medium testosterone production, steroidogenesis-related gene and protein expression, we found that: (1) ALDO suppressed EdU incorporation into SLCs at $100 \mathrm{nM}$ via mineralocorticoid receptor-mediated mechanism and (2) ALDO reduced Leydig cell number. In conclusion, ALDO pharmacologically blocked rat SLC development.

Keywords: mineralocorticoid, aldosterone, stem Leydig cells, proliferation, differentiation, testosterone

\section{INTRODUCTION}

Aldosterone (ALDO) is a cholesterol-derived steroid hormone and is a primary endogenous mineralocorticoid, controlling sodium and water homeostasis. ALDO binds to the mineralocorticoid receptor (NR3C2), a nuclear transcription factor, which undergoes hormone-dependent nuclear translocation and binds to specific hormone responsive elements, leading to the transactivation of various target genes (1). Besides its main regulation of water and sodium balance, its emerging roles in kidney, brain, heart and lung development has gained interest over the past few years.

In an early study, it was found that ALDO blocked the prepubertal development of testis and the differentiation of Leydig cells without causing atrophic changes in the interstitial elements (2), although the exact mechanism was unclear. Clinically, gonadal dysfunction, such as low sperm count and reduced motility, impotence, decreased libido, and infertility, were occasionally observed in patients undergoing long-term hemodialysis, whose serum testosterone was very low (3). Based on clinical findings, Adachi and Nakada found that five of six nephrectomized rats with renal failure had low serum testosterone levels and that ALDO level was remarkably high in the chronic renal failure rats after surgical ablation of more than about $80 \%$ of renal tissues, suggesting that enhanced renin-angiotensin-ALDO system contributes to gonadal impairment (4). 
Interestingly, it was found that rat Leydig cells expressed $\mathrm{NR} 3 \mathrm{C} 2$ and that ALDO stimulated testosterone production in adult Leydig cells via NR3C2 (5). A previous study also found a decreased plasma testosterone level after the ALDO receptor inhibitor spironolactone administration in men (6). This difference between prepubertal period and adulthood suggests that ALDO might have effects on stem Leydig cell (SLC) development.

Conceptually, the pubertal development in vivo of rat Leydig cells is divided into four stages: stem, progenitor, immature, and adult Leydig cells (7). This developmental process of Leydig cells can be mimicked in an established in vitro culture system, in which SLCs on the surface of the seminiferous tubules following ethane-dimethane-sulfonate (EDS)-induced Leydig cell deleption in vivo can be induced into the Leydig cell lineage after 14-21 days of culture $(8,9)$. The SLCs locate on the surface of the seminiferous tubules and they can either enter the proliferation or commit into the Leydig cell lineage in the presence of different growth factors $(8,9)$. SLCs can commit into the Leydig cell lineage, by expressing LH receptor (LHCGR, encoded by Lhcgr), high-density lipoprotein receptor (SCARB1, encoded by Scarb1), steroidogenic acute regulatory protein (StAR, encoded by Star), and androgen-biosynthetic enzymes, including cytochrome P450 cholesterol side-chain cleavage enzyme (CYP11A1, encoded by Cyp11a1), 3 $\beta$-hydroxysteroid dehydrogenase 1 (HSD3B1, encoded by $H s d 3 b 1$ ), cytochrome $17 \alpha$-hydroxylase/20-lyase (CYP17A1, encoded by Cyp17a1), 17 $\beta$-hydroxysteroid dehydrogenase 3 (HSD17B3, encoded by Hsd17b3), 11 $\beta$-hydroxysteroid dehydrogenase 1 (HSD11B1, encoded by Hsd11b1), and steroid $5 \alpha$-reductase 1 (SRD5A1, encoded by Srd5a1) (7). In the present study, we examined the effects of ALDO on rat SLC proliferation and differentiation in vitro.

\section{MATERIALS AND METHODS}

\section{Chemicals}

Aldosterone and RU28318 were purchased from Steraloids (Newport, RI, USA). Platelet-derived growth factor BB (PDGF-BB) was purchased from Sigma (St. Louis, MO, USA). DMEM/F-12 and Medium 199 culture media were purchased from Invitrogen (Carlsbad, CA, USA). LH was a gift of NIDDK (US). EDS was purchased from Pterosaur Biotech (Hangzhou, China).

\section{Animals}

Ninety-day-old (adult) male Sprague-Dawley rats were purchased from Shanghai Laboratory Animal Co. Ltd. (Shanghai, China) and were raised in a $12 \mathrm{~h}$ dark/light cycle temperatures at $23 \pm 2{ }^{\circ} \mathrm{C}$, and relative humidity of $45-55 \%$. Eighteen rats were adjusted for a week before they were subjected to the intraperitoneal injection (i.p.) of EDS (75 mg/kg). This dose was used to completely deplete Leydig cells according to the previous study (10). Animal procedures were approved by the Institutional Animal Care and Use Committee of Tongji University and were performed in accordance with the Guide for the Care and Use of Laboratory Animals by the National Research Council.

\section{Seminiferous Tubule Isolation and Culture}

Seven days after single i.p. of EDS when all Leydig cells were eliminated (11), seminiferous tubules were mechanically separated from the interstitium as previously described (11). The seminiferous tubules were distributed randomly into 12-well plates, with each well containing tubule fragments of equal total length (about $3 \mathrm{~cm}$ ). Tubules were cultured at $34^{\circ} \mathrm{C}$ and $5 \% \mathrm{CO}_{2}$ in a basal medium (BM), which has 1:1 mixture of DMEM/F-12 and Medium 199 (pH 7.2), sodium bicarbonate $(2.2 \mathrm{mg} / \mathrm{mL})$, bovine serum albumin $(1 \mathrm{mg} / \mathrm{mL})$, and penicillin $(100 \mathrm{U} / \mathrm{mL}) /$ streptomycin $(100 \mu \mathrm{g} / \mathrm{mL})$. ALDO $(0-100 \mathrm{nM})$, and/or RU28318 $(1 \mu \mathrm{M})$ were added to BM to investigate the effects on the proliferation of SLCs. RU28318 is a specific antagonist of NR3C2 (5).

The Leydig cell differentiation-inducing medium (LIM) was constructed by including $5 \mathrm{mM}$ ITS (insulin, transferrin, and selenium), $5 \mathrm{ng} / \mathrm{ml} \mathrm{LH}$, and $5 \mathrm{mM}$ lithium chloride as described (11). The previous study showed that seminiferous tubules in LIM were cultured for 14-21 days and SLCs on the surface of seminiferous tubules were fully differentiated into the Leydig cell lineage $(8,11,12)$. In this LIM, addition of ALDO $(0-100 \mathrm{nM})$ and/or RU28318 $(1 \mu \mathrm{M})$ (a NR3C2 antagonist) was performed to investigate the effects of ALDO on SLC differentiation and its mechanism. Concentrations of ALDO and RU28318 were selected according to the previous studies $(5,13)$. ALDO or RU21318 was dissolved in DMSO and an aliquot of ALDO or RU21318 was added to medium with the final concentration of DMSO as $0.1 \%$. Medium containing $0.1 \%$ DMSO served as the control.

Duplicated wells were used at each time point, and each experiment was replicated at least three times.

\section{Medium Testosterone Analysis}

Medium concentrations of testosterone were measured by IMMULITE $^{\circledR} 2000$ Total Testosterone Immunoassay Kit from Siemens (Gwynedd, UK). The duplicate assay for measurement of testosterone concentration in each medium was performed. The lower detection limit of testosterone was $0.2 \mathrm{ng} / \mathrm{mL}$. Blank medium and blank medium containing $100 \mathrm{nM}$ ALDO or $1 \mu \mathrm{M}$ RU21318, or $100 \mathrm{nM}$ ALDO $+1 \mu \mathrm{M}$ RU21318 were measured to check whether they influence the measurement of testosterone levels. No influence was found. The intra-assay and inter-assay CVs were 5.75 and $7.53 \%$, respectively.

\section{3及-Hydroxysteroid Dehydrogenase Enzymatic Staining to Label Leydig Cells}

Seminiferous tubules were cultured in BM or LIM for 14 days, and tubules then were air dried. Leydig cells on the surface of the tubules were evaluated by histochemical staining for HSD3B1 activity as described previously (14). Briefly, an aliquot of staining solution $(25 \mu \mathrm{L})$, containing $0.4 \mathrm{mM}$ etiocholanolone as the steroid substrate and $2 \mathrm{mM} \mathrm{NAD}^{+}$as the cofactor and nitro blue tetrazolium chloride as the staining substrate, was added on seminiferous tubules. The samples were incubated at room temperature for $30 \mathrm{~min}$. After staining, seminiferous tubules were 
washed using PBS and fixed with $4 \%$ paraformaldehyde at room temperature for $30 \mathrm{~min}$. The tubules were visualized in a light microscope.

\section{EdU Incorporation into SLCs}

Stem Leydig cell adheres to the surface and its DNA synthesis was measured by the Click-iT ${ }^{\circledR}$ EdU (EDU) Alexa Fluor ${ }^{\circledR} 488$ Imaging Kit (Life Technologies, OR, USA). A previous study demonstrated that PDGF-BB $(10 \mathrm{ng} / \mathrm{mL})$ robustly stimulated DNA synthesis in SLCs (15). Therefore, PDGF-BB (10 ng/ $\mathrm{mL}$ ) was used to increase DNA synthesis in SLCs. The isolated seminiferous tubules were cultured in BM with ALDO and/or RU28318 for the additional 5 days without (control) or with $10 \mathrm{ng} / \mathrm{ml}$ PDGF-BB. Then, EdU was supplied to the culture well and the samples were incubated for $24 \mathrm{~h}$. Tubules were washed, fixed in $4 \%$ paraformaldehyde, and incubated with reaction solution. EdU incorporation in SLCs was visualized under a fluorescence microscope (Olympus, Tokyo, Japan) and images were captured. EdU-positive cells were counted and calculated by the flat surface area of the seminiferous tubules using the Image Pro Plus 6.0 software (Media Cybernetics, Inc., MD, USA). A total of 20 seminiferous tubule images were counted. Some seminiferous tubules were embedded in $2 \%$ argose gel, fixed in $4 \%$ paraformaldehyde, and cross sections $(10 \mu \mathrm{m})$ were cut. Sections were incubated with mouse monoclonal antibody against $\alpha$-smooth muscle actin (SMA, Sigma, A2547, 1:200) and the conjugated secondary antibody (Donkey anti-Mouse IgG Secondary Antibody, Alexa Fluor ${ }^{\circledR}$ 594, Invitrogen, A-21203, 1:500) was used to visualize SMA. The EdU staining procedure was performed as above. The sections were visualized under immunofluorescence microscope.

\section{Cell Immunofluorescence to Identify Leydig Cells}

Seminiferous tubules were treated with or without ALDO and/or RU28318 in LIM for 14 days and were embedded in 2\% agarose gel, and cross sections $(10 \mu \mathrm{m})$ were cut as previously described (11). In brief, the sections were later fixed in $4 \%$ paraformaldehyde. Sections were washed and then incubated with mouse monoclonal anti-SMA antibody (1:200) and rabbit monoclonal antibody against HSD11B1 (Pterosaur Biotech, PB 10021, 1:500) for $60 \mathrm{~min}$ followed by incubation with conjugated secondary antibody (Alexa Fluor ${ }^{\circledR} 594$ for SMA) and (donkey anti-rabbit Dylight 488, Bioworld, BS10018, 1:100 for HSD11B1) for $30 \mathrm{~min}$. HSD11B1 was used to identify Leydig cells at the advanced stage because it begins expressed in rat Leydig cells starting on postnatal day 28 (16), when immature Leydig cells are emerged (17). SMA was used for labeling peritubular myoid cells (11). The sections were counterstained with DAPI (Sigma, D8417, $2 \mu \mathrm{g} / \mathrm{mL})$. HSD11B1-positive Leydig cells per tubule cross section were counted.

\section{Staining SLCs Using CD90 Antibody}

A previous study showed that $\mathrm{CD} 90^{+}$cells on the surface of the seminiferous tubules were SLCs (11). Seminiferous tubules were treated with or without 1-100 nM ALDO in BM for 5 days. The seminiferous tubules were washed using PBS containing 1\% BSA. Then, SLCs were stained using PE-conjugated CD90 antibody (Thermo Fisher Scientific, 12-0900-83, 1:100) in the dark place at $4^{\circ} \mathrm{C}$ for $45 \mathrm{~min}$. The tubules were mounted on a slide for visualization under a fluorescence microscope (Olympus, Japan) and images were captured. CD90-positive cells were counted and calculated by counting SLC number per $\mathrm{mm}^{2}$ flat surface area using the ImageProPlus 7.0 software (Media Cybernetics, USA).

\section{Real-time Quantitative Polymerase Chain Reaction (qPCR)}

Seminiferous tubules were treated with or without ALDO and/ or RU28318 in LIM for 14 days. Then tubules were washed and submerged to $0.5 \mathrm{~mL}$ Trizol ${ }^{\circledR}$ Reagent (Life Technologies, CA, USA), and total RNAs were extracted according to the manufacturer's instruction as described (11). The Leydig cell genes and their primers were used as described previously (18-20). Primers used for qPCR had at least one span intron. These genes include Lhcgr, Scarb1, Star, Cyp11a1, Hsd3b1, Cyp17a1, Hsd17b3, $S r d 5 a 1$, and $H s d 11 b 1$. The relative mRNA levels of targeted genes were normalized to Rps16 (internal control gene). The RNA was reversely transcribed into cDNA using Reverse Transcription System (Promega, WI, USA) according to the manufacturer's instruction. The qPCR was carried out in a $25-\mu$ l reaction volume with SYBR Green detection system (Bio-Rad Laboratories, Inc., CA, USA). Light Cycler $^{\circledR} 480$ SYBR Green I Master was purchased from Roche Diagnostics (IN, USA). Reactions were run on a Bio-Rad qPCR system (Bio-Rad Laboratories, Inc., CA, USA) for up to 40 cycles and the melting curves were routinely checked afterward. The Ct value was recorded and the standard curve method was used to calculate the gene expression levels as previously described (21).

\section{Western Blotting}

Seminiferous tubules were treated with or without ALDO and/or RU28318 in LIM for 14 days. Tubules were washed with PBS and submerged to the Radioimmunoprecipitation Assay Buffer (Beyotime Biotechnology, Shanghai, China) and homogenized to obtain total proteins. The protein concentrations of samples were measured with an Enhanced BCA Protein Assay Kit (Beyotime Biotechnology, Shanghai, China). An aliquot ( $50 \mu \mathrm{g}$ of proteins) of sample was added to gel well and electrophoresed on $10 \%$ polyacrylamide gels containing sodium dodecyl sulfate and proteins were transferred. Then, the membranes were incubated overnight at $4^{\circ} \mathrm{C}$ with primary antibodies against the following antigens: SCARB1 (MultiSciences, 70-ab1967-050, 1:1,000), LHCGR (MultiSciences, 70-ab7496$050,1: 1,000$ ), and $\beta$-actin (ACTB, Beyotime, AA128, 1:1,000). ACTB (house-keeping protein) served as the internal control. The membranes were then washed and incubated with HRPconjugated anti-rabbit IgG secondary antibody (MultiSciences, 70-GAR0072, 1:2,000) or HRP-conjugated anti-mouse IgG secondary antibody (MultiSciences, 70-GAM0072, 1:2,000) for $2 \mathrm{~h}$ at room temperature and washed. The immunoreactive bands were visualized by chemiluminescence using Western Bright ${ }^{\circledR}$ ECL (Advansta, CA, USA). The intensity of band was analyzed 


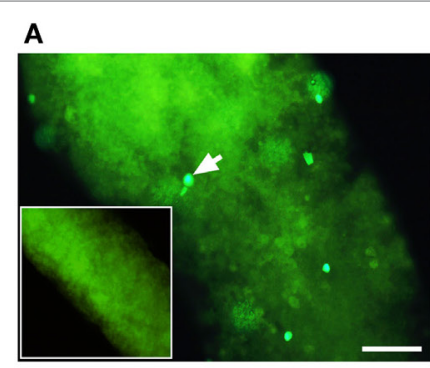

E

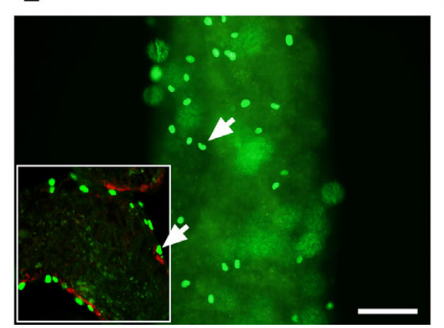

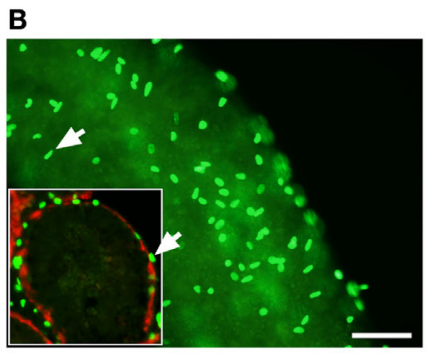

$\mathbf{F}$

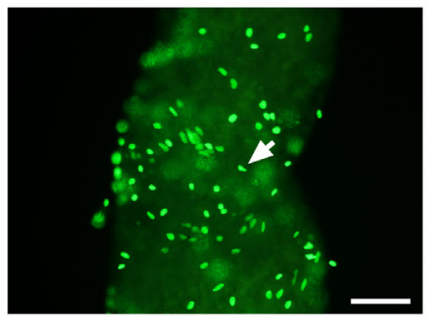

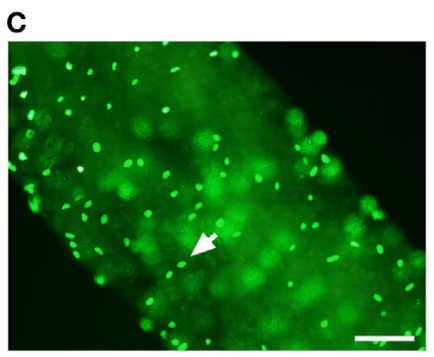

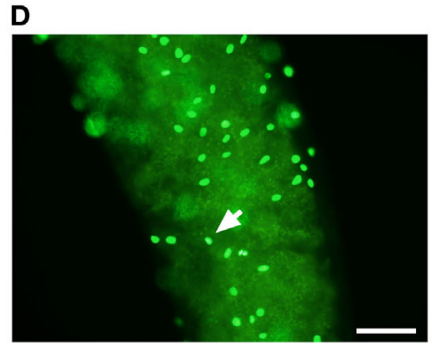

G

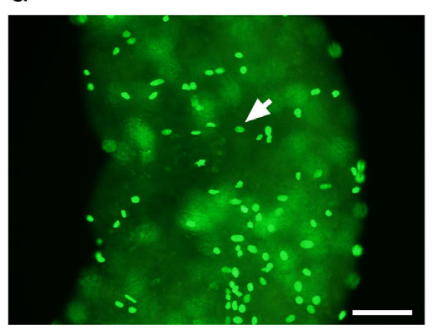

H

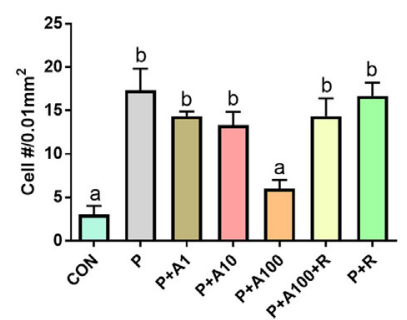

FIGURE 1 | EdU incorporation into stem Leydig cells (SLCs) after aldosterone (ALDO) treatment for 5 days. (A-G) EdU-labeled SLCs (green color in nuclei, arrow) in basal medium (A), with Platelet-derived growth factor BB (PDGF-BB) $10 \mathrm{ng} / \mathrm{mL}$ (B), with PDGF-BB $10 \mathrm{ng} / \mathrm{mL}+\mathrm{ALDO} 1 \mathrm{nM}$ (C), PDGF-BB $10 \mathrm{ng} / \mathrm{mL}+\mathrm{ALDO}$

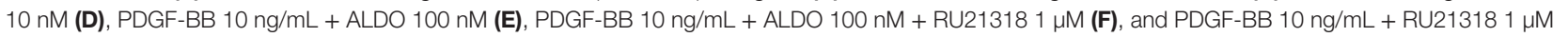
(G). (H) Quantitative data of EdU-incorporated cell number; bar $=40 \mu \mathrm{m}$. (A) Inset image presents negative control. (B,E) Inset images present the EdU incorporation in cross section; SMA (red color) represents peritubular myoid cells and green color represents EdU-incorporated cells (white arrow). $\mathrm{P}=$ PDGF-BB $10 \mathrm{ng} / \mathrm{mL}, \mathrm{A} 1-100=$ ALDO 1-100 nM, R = RU21318 $1 \mu \mathrm{M}$. Mean $\pm \mathrm{SD}, n=3$. Identical letters showed no significant difference between two groups at $P<0.05$.
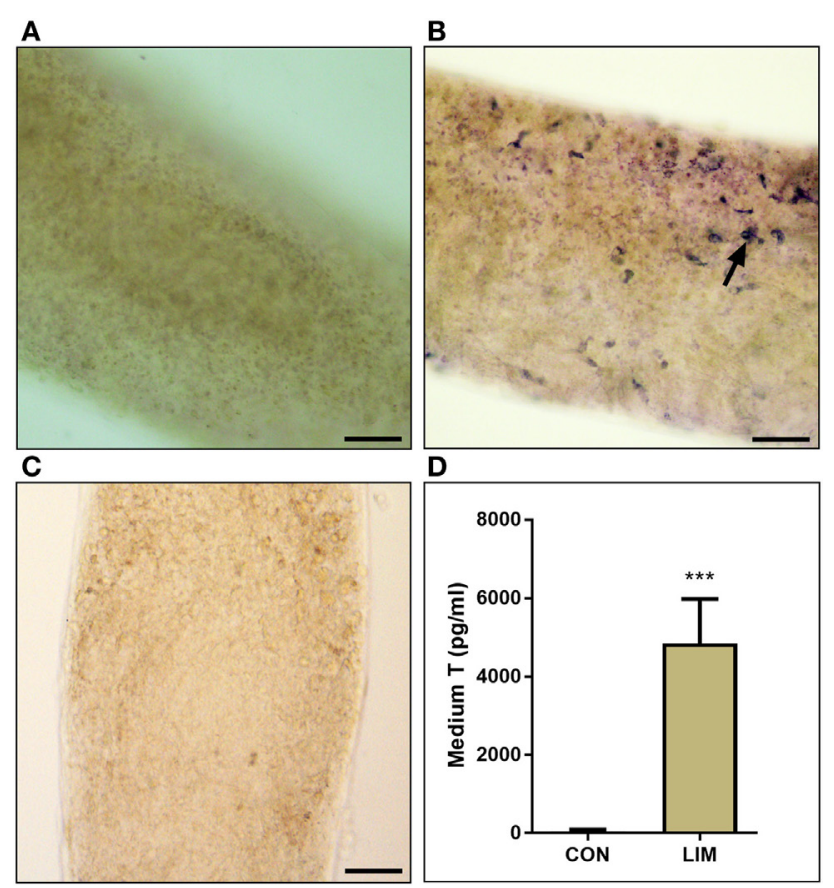

FIGURE 2 | 3ß-Hydroxysteroid dehydrogenase enzymatic staining to label Leydig cells and testosterone level. (A) Seminiferous tubule in basal medium (BM) for 14 days. (B) Seminiferous tubule in LIM for 14 days. Black arrow points to Leydig cells stained by $3 \beta$-hydroxysteroid dehydrogenase.

(C) Negative control. Bar $=50 \mu \mathrm{m}$. (D) Medium T levels in BM (CON) and LIM for 14 days. Mean $\pm \mathrm{SD}, n=6$; ${ }^{\star \star \star} P<0.001$ between control and LIM. with Image J software 1.51j8 (NIH, USA). The intensity was adjusted and calculated relative to the control (set as 100\%).

\section{Statistical Analysis}

Values are expressed as mean $\pm \mathrm{SD}$, and data were analyzed by the GraphPad Prism 6 (GraphPad Software Inc., CA, USA). After the normal distribution is confirmed, multiple groups were performed by one-way ANOVA followed by ad hoc Tukey's comparison of all columns compared with the control column. Mean value comparisons between two groups were performed by $\mathrm{t}$-test. Differences were considered significant at $P<0.05$.

\section{RESULTS}

\section{ALDO Inhibits SLC Proliferation}

To investigate the potential effects of ALDO on the proliferation of SLCs, we adopted an in vitro seminiferous tubule culture system. A previous study demonstrated that PDGF-BB $(10 \mathrm{ng} / \mathrm{ml})$ significantly increased EdU incorporation into the nuclei of SLCs (11). Isolated seminiferous tubules were cultured for 5 days with PDGF-BB $(10 \mathrm{ng} / \mathrm{mL})$ in the presence of $0-100 \mathrm{nM}$ ALDO and/or a NR3C2 antagonist RU28318, then, EdU incorporation into SLCs on the surface of seminiferous tubules was investigated. As shown in Figure 1A, in BM, there are a few EdU-incorporated SLCs present on the surface of the seminiferous tubules. PDGF-BB (10 ng/ml) remarkably increased EdUincorporated number of SLCs (Figure 1B), which were located 
on the surface of the seminiferous tubule (outside SMA-positive myoid cells, Figure 1B inset). When PDGF-BB plus 1-100 nM ALDO was used, ALDO concentration-dependently decreased PDGF-BB-stimulated EdU-incorporated SLCs (Figures 1C-E), with $100 \mathrm{nM}$ ALDO being significant difference compared to the control (Figure 1E). RU28318 (the NR3C2 antagonist) alone did not affect PDGF-BB-mediated EdU incorporation (Figure 1G), while it reversed the effect of $100 \mathrm{nM}$ ALDO (Figure 1F). This suggests that ALDO suppresses SLC proliferation via binding to NR3C2. Quantitative data of EdU incorporated cell number was summarized (Figure 1H).
We cultured the seminiferous tubules in BM (control) or LIM for 14 days. No HSD3B1-positive Leydig cells were formed in the control (Figure 2A), while many HSD3B1-positive Leydig cells were formed on the surface of the seminiferous tubule after culture with LIM (Figure 2B). Apparently, significantly higher level of testosterone was produced by the Leydig cells after culture with LIM (Figure 2D). This confirms the previous observation that LIM is an inducer for SLC differentiation.

To further examine whether ALDO can affect the pool of SLCs, the seminiferous tubules were cultured in BM with various concentrations of ALDO (0-100 nM) and/or RU28318 for 7 days
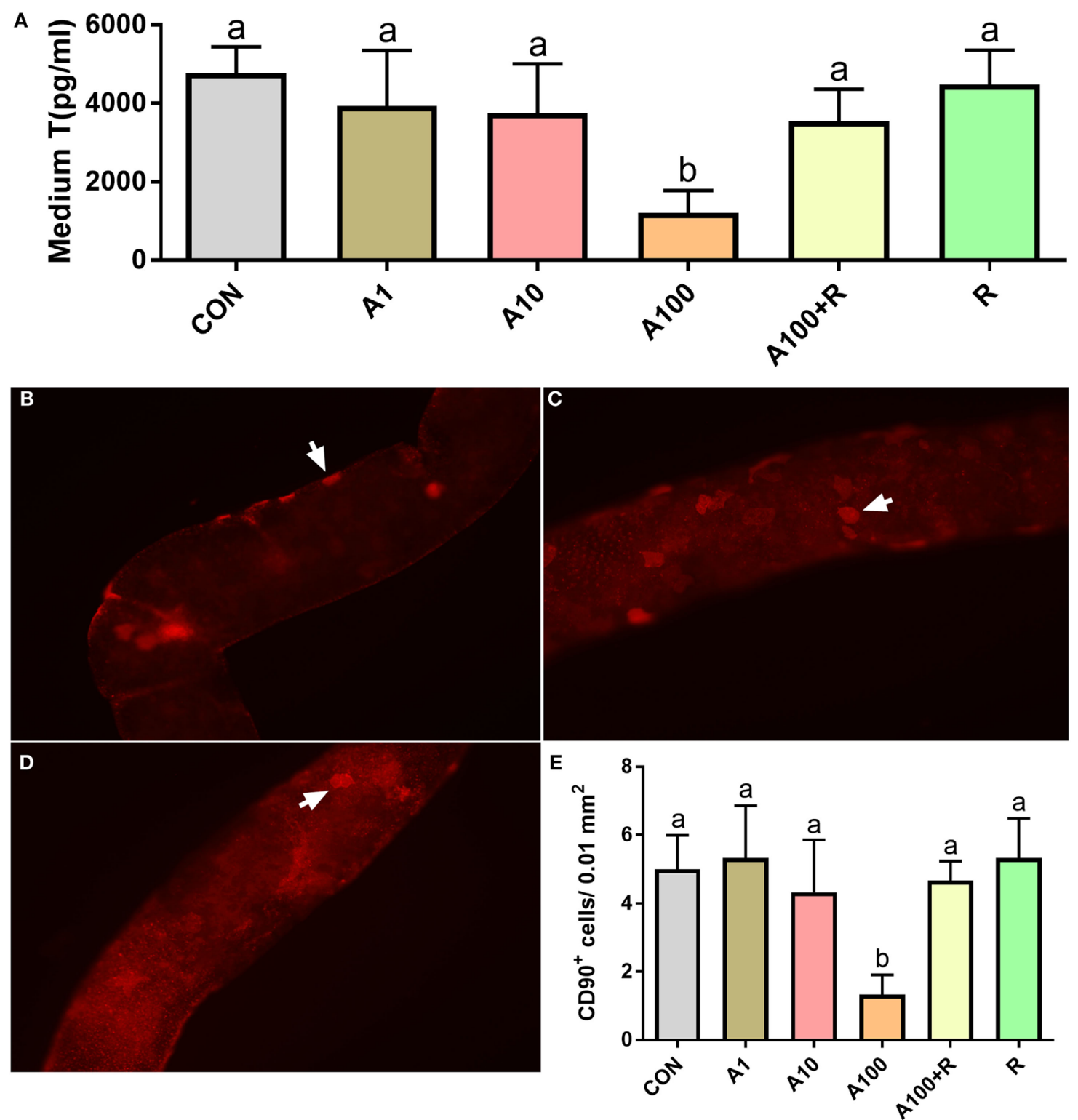

FIGURE 3 | Effects of aldosterone (ALDO) on stem Leydig cell (SLC) proliferation and CD90-positive SLC number. Seminiferous tubules were cultured in basa medium (BM) with various concentrations of ALDO and/or RU28318 for 7 days and then were switched into LIM for additional 14 days, medium testosterone (T) levels were measured (mean $\pm \mathrm{SD}, n=4-8)$. (A) ALDO (0-100 nM) and/or RU21318, A1-100 = ALDO 1-100 nM, R = RU21318 $1 \mu \mathrm{M}$. Images of CD90-positive cells at ALDO $0 \mathrm{nM}$ (B), at ALDO $10 \mathrm{nM}$ (C), and ALDO $100 \mathrm{nM}$ (D) in BM for 5 days; white arrow points to CD90-positive SLC. (E) Quantitative data of CD90positive cells after ALDO and RU28318 treatment; mean $\pm \mathrm{SD}, n=3$. Identical letters showed no significant difference between two groups at $P<0.05$. 
and then the seminiferous tubules were switched into LIM for additional 14 days to induce these SLCs into the Leydig cells. Testosterone levels in the medium were significantly decreased at $100 \mathrm{nM}$ ALDO (Figure 3A), and its effect was reversed by RU28318, indicating the effect was acted via binding to NR3C2 (Figure 3A). A previous study demonstrated that CD90-positive cells were SLCs (11). After 5 days of treatment with 0-100 nM ALDO in BM, we found that ALDO (100 nM) significantly lowered CD90-positive SLC number and the effect was reversed by RU28318 (Figures 3B-E).

\section{ALDO Affects SLC Differentiation}

The seminiferous tubules were continuously cultured in LIM for 14 days to induce SLCs into adult Leydig cells, thus producing testosterone as in Figure 2D. When various concentrations of ALDO were added in LIM and the seminiferous tubules were cultured for 14 days. ALDO decreased the HSD11B1-positive Leydig cell numbers at $\geq 10 \mathrm{nM}$ and RU28318 reversed the ALDO-mediated effects (Figures 4A-F). ALDO decreased medium testosterone levels at $\geq 10 \mathrm{nM}$ and RU28318 (1 $\mu \mathrm{M})$ alone did not affect the SLC differentiation (Figure 4G). After adjustment by the Leydig cell numbered, it was found that $10 \mathrm{nM}$ ALDO increased medium testosterone levels (Figure $\mathbf{4 H}$ ). This indicates that ALDO stimulates Leydig cell differentiation of the existing stem cells.

\section{ALDO Alters Leydig Cell-Specific Genes and Protein Expression}

We examined the effects of ALDO on the expression levels of Leydig cell-specific genes (Figure 5A). Statistically, we found
ALDO significantly reduced the Scarb1 (encoding SCARB1) level at $\geq 10 \mathrm{nM}$ and Lhcgr (encoding LHCGR) level $\geq 100 \mathrm{nM}$. However, ALDO did not affect other seven gene mRNA levels. However, we further calculated Lhcgr, Scarb1, Star, Cyp11a1, $H s d 3 b 1, C y p 17 a 1, H s d 17 b 3, S r d 5 a 1$, and Hsd11b1 levels after adjustment of Leydig cell number (Figure 6) and we found that ALDO actually increased the expression levels of all these genes at $10 \mathrm{nM}$ and higher. In parallel, we also selected two important Leydig-cell specific proteins, SCARB1 and LHCGR, and we found the levels of these two proteins were reduced by ALDO (Figure 5B or Figure S1-S3 adapted to ImageJ Software). However, ALDO increased SCARB1 and LHCGR protein levels per cell after adjustment of Leydig cells (Figure 6). RU28318 reversed ALDO-mediated effects. These results indicate that ALDO inhibits the proliferation of SLCs by lowering Leydig cell number but induces the differentiation of SLCs via increasing the Leydig cell specific gene expression.

\section{DISCUSSION}

Mineralocorticoid is pivotal during the perinatal period in many target tissues. In this research, we mainly focused on the developmental specificities of the primary endogenous mineralocorticoid ALDO in rat SLCs. We found that ALDO targeted SLCs to inhibit their proliferation.

In the present study, SLCs in the medium containing ITS, LH, and LI (LIM) could be induced into testosterone-producing Leydig cells in vitro (Figure 2), confirming the previous observation (11). In the non-LIM medium, Leydig cells cannot be induced because Leydig cell biomarker CYP11A1 was not expressed (11). Benefiting from this system, we could examine
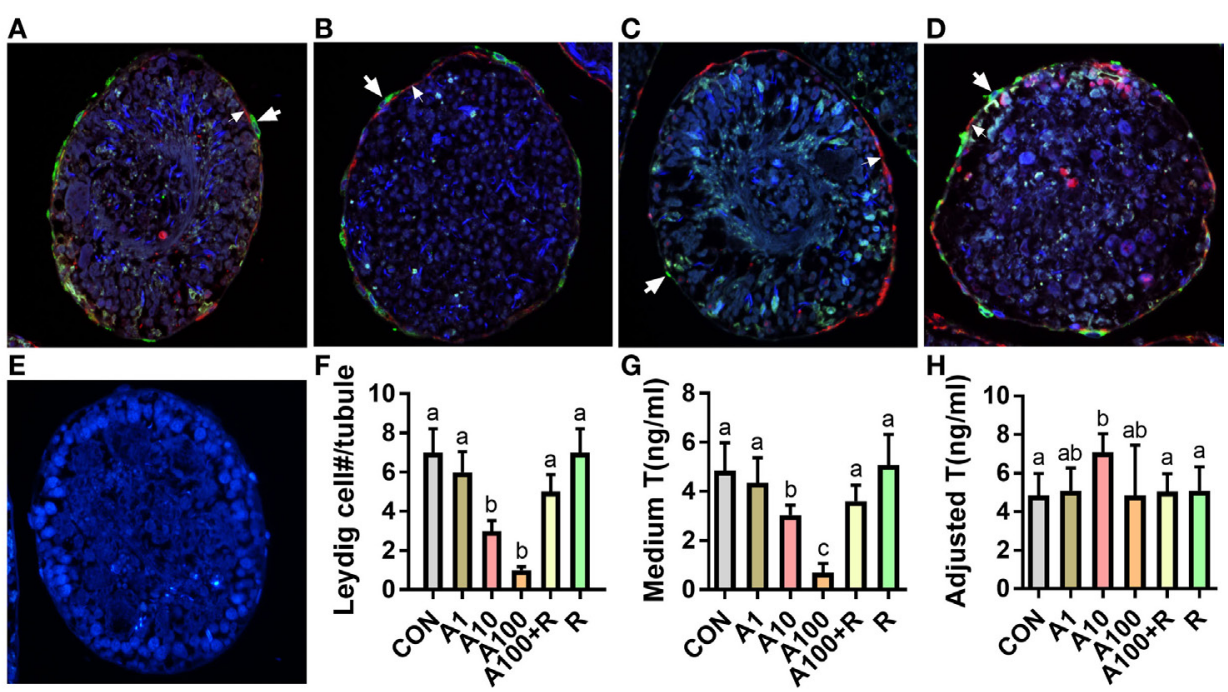

FIGURE 4 | Aldosterone reduces the formation of Leydig cells. (A-G) Immunofluorescent staining of tubule cross section after aldosterone (ALDO) and/or RU21318 treatment in LIM for 14 days. Cross sections with HSD11B1 staining (green color, thick arrow) showed the formation of Leydig cells. $\alpha$-Smooth muscle actin staining (red color, thin arrow) showed the myoid cells, which circled the seminiferous tubules. HSD11B1-positive cells were outside the $\alpha$-smooth muscle actin-positive cells, indicating that they were differentiated from the stem Leydig cells (SLCs) on the surface of the tubule. (A) ALDO 0 nM; (B) ALDO 10 nM; (C) ALDO $100 \mathrm{nM}$; (D) ALDO $100 \mathrm{nM}+\mathrm{RU} 213181 \mu \mathrm{M}$; (E) negative control; and (F) quantitative data of Leydig cell number per cross section; mean \pm SD, $\mathrm{n}=3$. (G) Quantitative data of testosterone level after ALDO treatment, mean $\pm \mathrm{SD}, n=6$. $\mathbf{( H )}$ Quantitative data of adjusted testosterone level after ALDO treatment by Leydig cell number, mean $\pm \mathrm{SD}, n=6$. Identical letters showed no significant difference between two groups at $P<0.05$. 


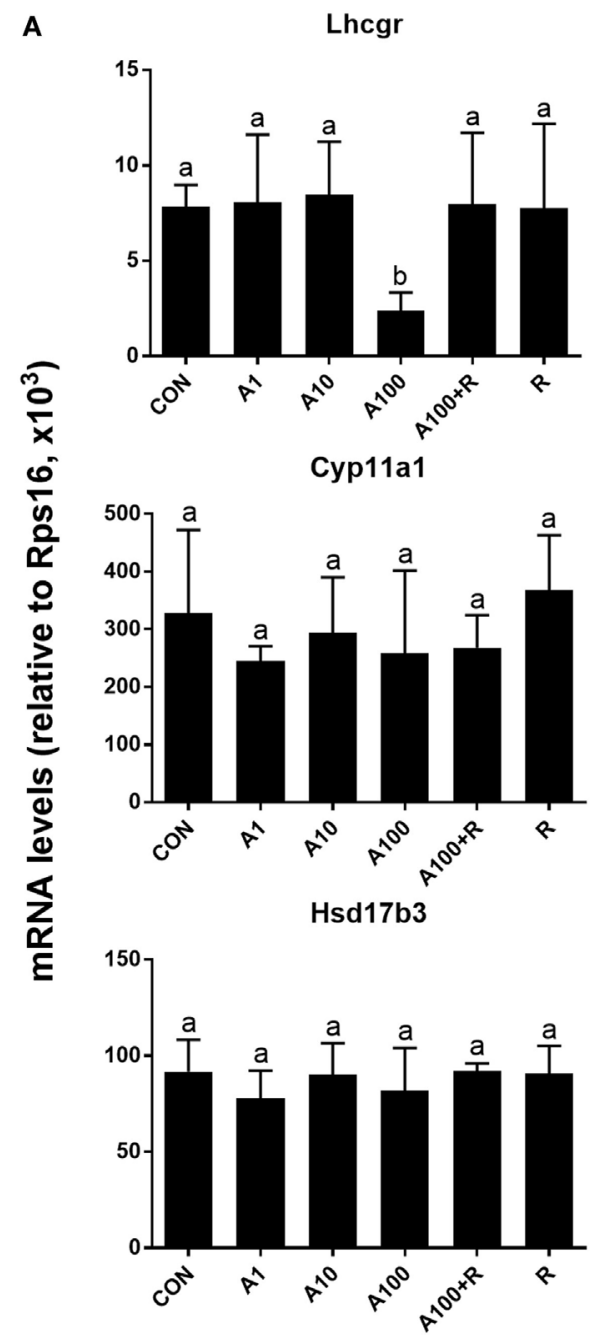

B
Scarb1

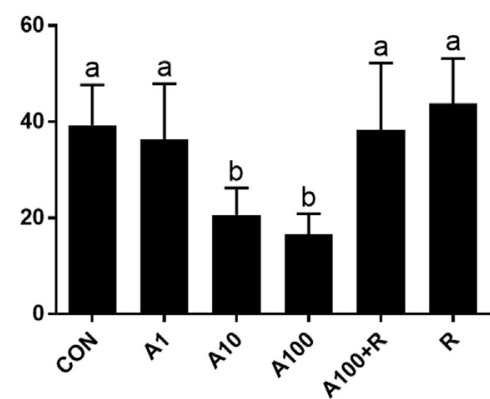

Hsd3b1
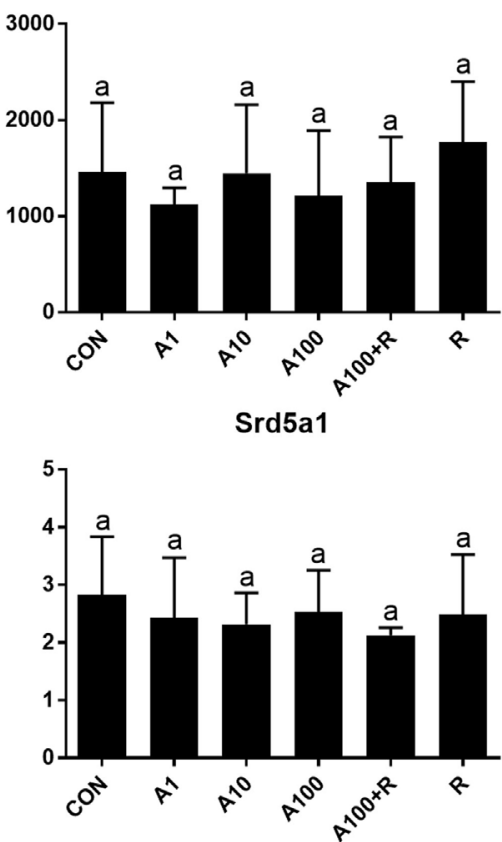

LHCGR

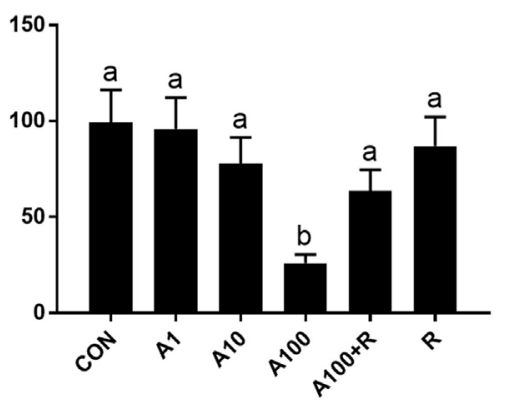

Star

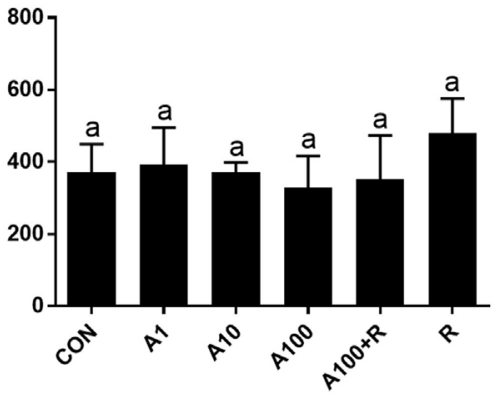

Cyp17a1

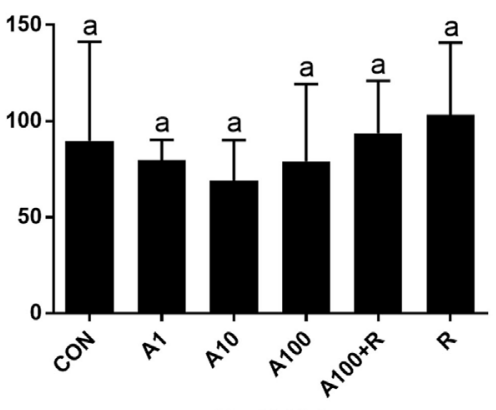

Hsd11b1

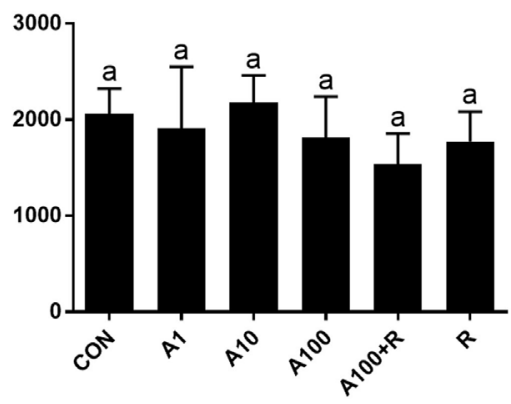

SCARB1

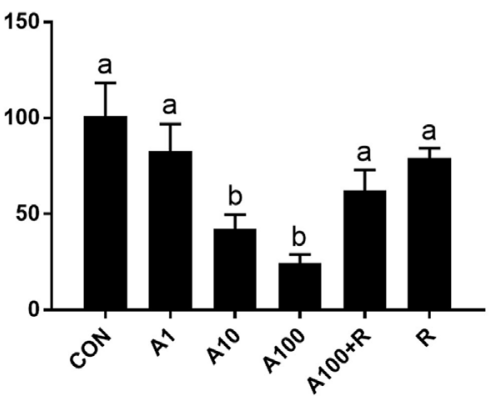

Intensity (\%CON)

FIGURE 5 | Aldosterone (ALDO) reduces Leydig cell-specific gene and its protein expression levels. Seminiferous tubules were cultured in LIM in the presence of ALDO and/or RU21318 for 14 days, then mRNA levels of Leydig cell-specific mRNA levels were measured by quantitative polymerase chain reaction ( $n=4-6)$, and SCARB1 and LHCGR levels were measured by Western blot $(n=3)$. A1-100 = ALDO 1-100 nM, R= RU21318 $1 \mu$ M. (A) mRNA; (B) protein; mean \pm SD. Identical letters showed no significant difference between two groups at $P<0.05$.

ALDO to regulate SLC differentiation and proliferation without the interference by hypothalamus-pituitary secreted hormones. In this system, we demonstrated that ALDO suppressed the proliferation of SLCs in vitro via NR3C2-induced effects, because the NR3C2 antagonist RU28318 could reverse its action. 


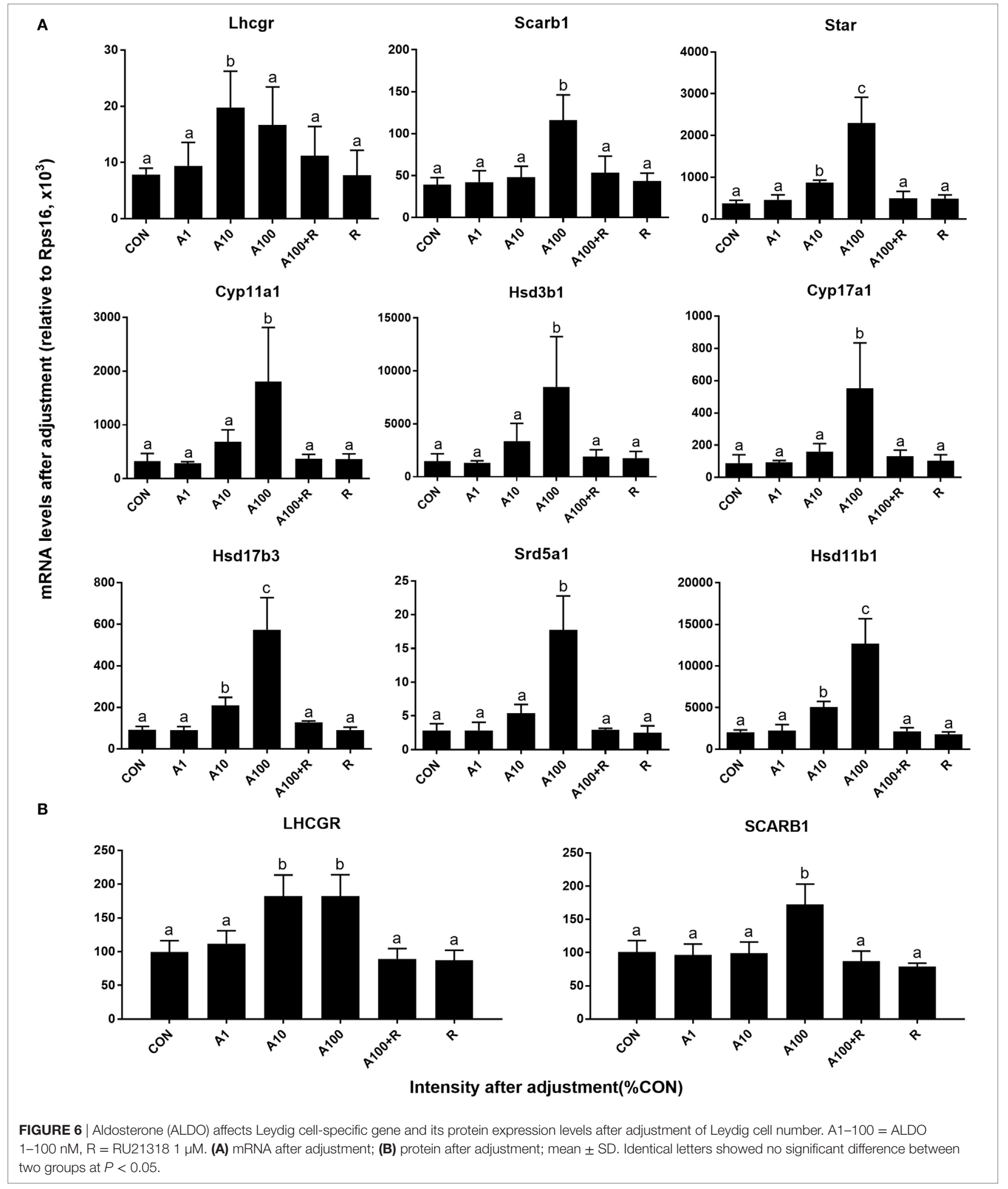

The present study demonstrated that ALDO suppressed the proliferation of SLCs in vitro and ALDO-induced effects. Interestingly, ALDO increased many Leydig cell-specific gene (such as Lhcgr, Scarb1, Star, Cyp11a1, Hsd3b1, Cyp17a1, $H s d 17 b 3, S r d 5 a 1$, and Hsd11b1) expression level after adjustment of Leydig cell number, suggesting that ALDO stimulates 
Leydig cell gene expression. Thus, ALDO increased testosterone production in Leydig cells per se (Figure $4 \mathbf{H}$ ). However, ALDO significantly reduced Leydig cell numbers, thus reducing testosterone production in the medium. This conforms to our previous observation that ALDO acutely stimulated testosterone production in adult Leydig cells. Evidently, ALDO acted via NR3C2, because the NR3C2 antagonist RU28318 reversed ALDO-mediated alteration of the gene expression of Leydig cell genes such as Lhcgr, Scarb1, Star, Cyp11a1, Hsd3b1, Cyp17a1, Hsd17b3, Srd5a1, and Hsd11b1 (Figures 5 and 6) and testosterone levels (Figure 4). ALDO affected SLC function in a pharmacological concentration (at $\geq 10 \mathrm{nM}$ ). Indeed, ALDO blocked the development of rat Leydig cells at pharmacological doses (2). Clinically, a decreased plasma testosterone level was found in men with the ALDO receptor inhibitor spironolactone administration (6), and enhanced renin-angiotensin-ALDO system (with increase of ALDO levels) might also contribute to gonadal impairment (4). Other clinical data was lacking and further clinical investigation for ALDO action on Leydig cell development is required.

Interestingly, unlike the effects of ALDO on SLC function as shown in the present study, ALDO stimulated testosterone production in rat adult Leydig cells via an MR-mediated mechanism (5). Although ALDO stimulated the Leydig cell specific gene expression and testosterone production per se, it significantly reduced testosterone production by decreasing the Leydig cell number. The developmentally different effects that ALDO exerted on Leydig cell development are still unclear. We speculate that the different ALDO-NR3C2 action on Leydig cells at different stages may depend on intracellular NR3C2 binding proteins. Indeed, NR3C2 actions were regulated by chaperone proteins such as heat shock proteins 90 and 70 (hsp90 and hsp70)

\section{REFERENCES}

1. Viengchareun S, Le Menuet D, Martinerie L, Munier M, Pascual-Le Tallec L, Lombes M. The mineralocorticoid receptor: insights into its molecular and (patho)physiological biology. Nucl Recept Signal (2007) 5:e012. doi:10.1621/ nrs.05012

2. Kar AB, Roy SN, Das RP. Effect of aldosterone monoacetate and desoxycorticosterone acetate on the testis of young rats. Acta Endocrinol (1958) 29(3):361-8.

3. Lim VS, Fang VS. Gonadal dysfunction in uremic men. A study of the hypothalamo-pituitary-testicular axis before and after renal transplantation. Am J Med (1975) 58(5):655-62. doi:10.1016/0002-9343(75)90501-X

4. Adachi Y, Nakada T. Effect of experimentally induced renal failure on testicular testosterone synthesis in rats. Arch Androl (1999) 43(1):37-45. doi:10.1080/014850199262715

5. Ge RS, Dong Q, Sottas CM, Latif SA, Morris DJ, Hardy MP. Stimulation of testosterone production in rat Leydig cells by aldosterone is mineralocorticoid receptor mediated. Mol Cell Endocrinol (2005) 243(1-2):35-42. doi:10.1016/j. mce.2005.08.004

6. Baba S, Murai M, Jitsukawa S, Hata M, Tazaki H. Antiandrogenic effects of spironolactone: hormonal and ultrastructural studies in dogs and men. J Urol (1978) 119(3):375-80. doi:10.1016/S0022-5347(17)57495-9

7. Ye L, Li X, Li L, Chen H, Ge RS. Insights into the development of the adult Leydig cell lineage from stem Leydig cells. Front Physiol (2017) 8:430. doi:10.3389/fphys.2017.00430

8. Odeh HM, Kleinguetl C, Ge R, Zirkin BR, Chen H. Regulation of the proliferation and differentiation of Leydig stem cells in the adult testis. Biol Reprod (2014) 90(6):123. doi:10.1095/biolreprod.114.117473 and immunophylins $(22,23)$ and posttranslational modifications such as phosphorylation, ubiquitinylation, sumoylation, and acetylation as well as interactions with many coregulators (23).

In conclusion, ALDO inhibited the proliferation of SLCs via NR3C2, thus leading to the reduced Leydig cell number and testosterone production, although it stimulated the expression of Leydig cell genes and testosterone production in the single cell.

\section{ETHICS STATEMENT}

Animal procedures were approved by the Institutional Animal Care and Use Committee of Tongji University and were performed in accordance with the Guide for the Care and Use of Laboratory Animals by the National Research Council.

\section{AUTHOR CONTRIBUTIONS}

JZ, BH, GH, XZhan, TX, SL, XZhang, and HL performed experiments; JZ, BH, and GH analyzed data; R-SG and YX designed experiments and wrote the manuscript.

\section{FUNDING}

This work was supported by National Natural Science Foundation of China (nos. 81370699 and 81671446).

\section{SUPPLEMENTARY MATERIAL}

The Supplementary Material for this article can be found online at https://www.frontiersin.org/articles/10.3389/fendo.2018.00004/ full\#supplementary-material.

9. Stanley E, Lin CY, Jin S, Liu J, Sottas CM, Ge R, et al. Identification, proliferation, and differentiation of adult Leydig stem cells. Endocrinology (2012) 153(10):5002-10. doi:10.1210/en.2012-1417

10. Teerds KJ, De Rooij DG, Rommerts FF, Wensing CJ. The regulation of the proliferation and differentiation of rat Leydig cell precursor cells after EDS administration or daily HCG treatment. J Androl (1988) 9(5):343-51. doi:10.1002/j.1939-4640.1988.tb01061.x

11. Li X, Wang Z, Jiang Z, Guo J, Zhang Y, Li C, et al. Regulation of seminiferous tubule-associated stem Leydig cells in adult rat testes. Proc Natl Acad Sci U S A (2016) 113(10):2666-71. doi:10.1073/pnas. 1519395113

12. Zhang L, Wang H, Yang Y, Liu H, Zhang Q, Xiang Q, et al. NGF induces adult stem Leydig cells to proliferate and differentiate during Leydig cell regeneration. Biochem Biophys Res Commun (2013) 436(2):300-5. doi:10.1016/j. bbrc.2013.05.098

13. Xiao YC, Huang YD, Hardy DO, Li XK, Ge RS. Glucocorticoid suppresses steroidogenesis in rat progenitor Leydig cells. J Androl (2010) 31(4):365-71. doi:10.2164/jandrol.109.009019

14. Payne AH, Wong KL, Vega MM. Differential effects of single and repeated administrations of gonadotropins on luteinizing hormone receptors and testosterone synthesis in two populations of Leydig cells. J Biol Chem (1980) 255(15):7118-22.

15. Chen H, Wang Y, Ge R, Zirkin BR. Leydig cell stem cells: identification, proliferation and differentiation. Mol Cell Endocrinol (2016) 445:65-73. doi:10.1016/j.mce.2016.10.010

16. Phillips DM, Lakshmi V, Monder C. Corticosteroid 11 $\beta$-dehydrogenase in rat testis. Endocrinology (1989) 125(1):209-16. doi:10.1210/endo-125$1-209$ 
17. Ge RS, Hardy MP. Variation in the end products of androgen biosynthesis and metabolism during postnatal differentiation of rat Leydig cells. Endocrinology (1998) 139(9):3787-95. doi:10.1210/endo.139.9.6183

18. Guo J, Zhou H, Su Z, Chen B, Wang G, Wang CQF, et al. Comparison of cell types in the rat Leydig cell lineage after ethane dimethanesulfonate treatment. Reproduction (2013) 145(4):371-80. doi:10.1530/REP-12-0465

19. Guo J, Deng H, Li H, Zhu Q, Zhao B, Chen B, et al. Effects of methoxychlor and its metabolite 2,2-bis(p-hydroxyphenyl)-1,1,1-trichloroethane on $11 \beta$-hydroxysteroid dehydrogenase activities in vitro. Toxicol Lett (2013) 218(1):18-23. doi:10.1016/j.toxlet.2013.01.002

20. Lin H, Ge RS, Chen GR, Hu GX, Dong L, Lian QQ, et al. Involvement of testicular growth factors in fetal Leydig cell aggregation after exposure to phthalate in utero. Proc Natl Acad Sci U S A (2008) 105(20):7218-22. doi:10.1073/pnas.0709260105

21. Liu S, Chen X, Wang Y, Li L, Wang G, Li X, et al. A role of KIT receptor signaling for proliferation and differentiation of rat stem Leydig cells in vitro. Mol Cell Endocrinol (2017) 444:1-8. doi:10.1016/j.mce.2017.01.023

22. Czar MJ, Galigniana MD, Silverstein AM, Pratt WB. Geldanamycin, a heat shock protein 90-binding benzoquinone ansamycin, inhibits steroid- dependent translocation of the glucocorticoid receptor from the cytoplasm to the nucleus. Biochemistry (1997) 36(25):7776-85. doi:10.1021/ bi970648x

23. Pascual-Le Tallec L, Lombes M. The mineralocorticoid receptor: a journey exploring its diversity and specificity of action. Mol Endocrinol (2005) 19(9):2211-21. doi:10.1210/me.2005-0089

Conflict of Interest Statement: The authors declare that the research was conducted in the absence of any commercial or financial relationships that could be construed as a potential conflict of interest.

Copyright (c) 2018 Zhang, Huang, Hu, Zhan, Xie, Li, Zhang, Li, Ge and Xu. This is an open-access article distributed under the terms of the Creative Commons Attribution License (CC BY). The use, distribution or reproduction in other forums is permitted, provided the original author(s) or licensor are credited and that the original publication in this journal is cited, in accordance with accepted academic practice. No use, distribution or reproduction is permitted which does not comply with these terms. 